\title{
Photocoagulation for proliferative diabetic retinopathy: a randomised controlled clinical trial using the xenon-arc
}

\author{
British Multicentre Study Group \\ Participating centres and ophthalmologists: M. Odland, Bergen, Norway; R. K. Blach, A. M. Hamilton, P. K. Leaver, and C. Townsend, \\ Hammersmith/Moorfields, London; H. Cheng, Kent \& Sussex Hospital Tunbridge Wells; E. W. G. Davies, King's College Hospital, London; \\ J. Richardson, Newcastle Eye Infirmary; T. ffytche and J.Shilling St. Thomas's Hospital London. \\ Statisticians: P. Armitage and E. Hoinville. \\ Medical Advisors: H. Keen and E. M. Kohner. \\ Report prepared by: E. M. Kohner, P.K. Leaver and E. Hoinville
}

\begin{abstract}
Summary. The final results of a randomised controlled study of xenon-arc photocoagulation for proliferative retinopathy are reported, after all patients have been followed for at least 5 years and some for up to 7 years. One hundred and seven patients with two similarly affected eyes had one treated (chosen by a random procedure), while the other eye remained untreated and served as a control. Of the 107 patients, 77 completed the 5 year follow up, 13 died and 17 stopped attending for various reasons. Of the recorded coexistent medical abnormalities, only renal complications affected survival, none influenced visual outcome. Visual outcome was significantly better in the treated than in the control eyes at each yearly interval $(0.001<p<0.05)$. The greatest difference was seen in those with disc vessels at entry. In this group, control eyes deteriorated by a mean of four lines on the Snellen chart,
\end{abstract}

treated eyes by one line only. Six patients became legally blind in both eyes, four were blind in the treated eye only, but 28 control eyes were blind when treated eyes retained vision $(p<0.001)$. Treated eyes which became blind had less treatment than those that retained vision. Of the 42 treated eyes with peripheral new vessels only at entry, 12 developed disc new vessels. These 12 had fewer burns than the 30 which did not develop disc new vessels. It is concluded that in proliferative retinopathy, treatment by photocoagulation is better than no treatment at all. Adequate treatment is required to maintain vision.

Key words: Diabetic retinopathy, proliferative retinopathy, xenon-arc photocoagulation, randomised controlled clinical trial.
Since the introduction of photocoagulation for the treatment of diabetic retinopathy by Meyer-Schwickerath [1], three randomised controlled clinical trials have shown its effectiveness in the treatment of proliferative lesions, particularly those which arise from the optic $\operatorname{disc}[2-5]$.

The present communication is the final report of one of these studies [3], when all patients have been followed for at least 5 years.

\section{Patients and methods}

\section{Patients}

Patients with proliferative retinopathy in both eyes were considered for the study. The retinopathy had to be of similar severity in both eyes, i. e. within two grades using the Hammersmith Hospital grading system [6]. This system is based on grading retinal lesions of major importance (microaneurysms and haemorrhages, hard exudates, new vessels and fibrous retinitis proliferans) by comparison with standard photographs. There are four standard photographs for each lesion spanning the full range of severity A-D. This allows six steps of sever- ity grading for each lesion. A lesion can be absent, grade $0 ; 1$ which is better than standard A, 2 which is equal to or worse than standard A, but better than standard B etc, 5 being the worst possible for that lesion. It did not matter whether the new vessels arose from the disc or the retinal periphery. The visual acuity in the two eyes had to be within two lines on the Snellen chart and the vision in the worse eye had to be $6 / 60$ or better. Patients as described above were eligible irrespective of age or duration of diabetes if they fulfilled the following criteria: (1) There was no, or not more than a wisp of, fibrous retinitis proliferans present (<grade 1 of the Hammersmith Hospital grading system [6]). (2) There was no concomitant eye disease which interfered with the photography, assessment or prognosis of the retinopathy. Thus, patients who had had any previous photocoagulation or eye surgery were excluded, as were patients receiving systemic or local therapy for any eye condition. Patients with congenital lesions and amblyopia were also excluded, as were those who had significant assymmetry or refraction (over 2 dioptres). (3) The patient's general health was such that he/she was expected to be followed for 5 years. (4) The patients gave their informed consent for only one eye to be treated and the other to be followed as an untreated control.

There were 107 patients from six participating centres (Hammersmith/Moorfields Hospitals, King's College Hospital and St Thomas' Hospital, London; Kent and Sussex Hospital; Newcastle Eye Infirmary and Bergen Hospital, Norway) who fulfilled the entry criteria and were included in the study. Clinical variables at entry are shown in Tables 1-4. 
Table 1. Age of onset and duration of diabetes at entry into study

\begin{tabular}{lcccc}
\hline $\begin{array}{l}\text { Known duration of } \\
\text { diabetes (years) }\end{array}$ & $\begin{array}{l}\text { Age at diagnosis of diabetes } \\
\text { (years) }\end{array}$ & Total \\
\cline { 2 - 4 } & $0-29$ & $30-59$ & $\geqslant 60$ & \\
\hline $0-5$ & 1 & 19 & 3 & 23 \\
$6-10$ & 0 & 6 & 1 & 7 \\
$11-15$ & 11 & 4 & 0 & 15 \\
$16-20$ & 22 & 3 & 0 & 25 \\
Over 20 & 29 & 3 & 0 & 32 \\
\hline Total & 63 & 35 & 4 & 102 \\
\hline
\end{tabular}

Data were missing in five patients

\section{Procedure}

After ascertaining the patient's suitability for the trial and obtaining his/her consent for the study, the disc and macular fields of both eyes were photographed. The eye to be treated was determined by a random assignment, prepared at the coordinating centre, and indicated in a sealed envelope, marked with the patient's serial number and opened after the patient's entry into the trial.

\section{Treatment}

Treatment was started as soon as possible after randomisation under local (retrobulbar) or general anaesthesia, using the xenon-arc photocoagulator (Zeiss, Oberkochen, FRG or O'Malley, Palo Alto, California, USA). The number of burns given was not specified, but advice was given to treat all peripheral new vessels focally, destroying the vessels as far as possible with a rim of photocoagulation extending approximately one-quarter of the dise diameter beyond the edge of the lesions. Disc new vessels could be treated directly if they came off the disc in the nasal, superior or inferior quadrants. In addition to focal treatment, pattern bombing or scatter treatment could be given to patients with peripheral new vessels in addition to focal treatment, but was not mandatory. Scatter treatment was advised for new vessels arising from the disc, but the number of burns was not specified. Burns were not to be given within 1 disc diameter from the centre of the fovea. The individual burns were of $3^{\circ}$ size with a 1 -s exposure in the periphery and $1^{\circ}$ in the perimacular area, the power varying between setting II and VIII; the aim being to achieve the slightest visible whitening of the retina.

The initial treatment could be given in one or more sessions during the first 3 months. Treated eyes could be retreated at any time if further new vessels developed or the vessels present initially became worse. The control eye remained untreated until after 1977, when the British Multicentre Study report became available and significant benefit from treatment in disc new vessels was observed [3]. Thereafter, the control eye could be treated if it had disc new vessels worse than Hammersmith Hospital grade 1 [7]. There were only two such eyes and these patients were excluded from further analysis. A further 28 were considered already untreatable.

Yearly eye examination, photographic grading and relevant medical details were obtained as near as possible to the anniversary of entry into the study and a computer used for their analysis.

Eye examination included the best corrected visual acuity obtained on the Snellen chart (taken when possible by an optician unaware of which eye was treated). The Snellen chart was a standard back-illuminated model and no further effort of standardisation between clinics was performed. However, in each centre, the same chart was used throughout the study and the treated and control eyes were treated similarly. Full clinical examination of the eye was performed, including slit lamp biomicroscopy and indirect and direct ophthalmoscopy. Photographs (non-stereoscopic) of the disc and macular fields were taken. Fluorescein angiography did not form part of the study. For photographic grading, the Hammersmith Hospital grading system was used $[6,7]$.

\section{Statistical methods}

For statistical analysis, the paired t-test, McNemar's test [8] and Chisquare test were used. A paired $t$-test was used to compare treated and control eyes for mean visual acuity and the change of vision at each yearly interval for treated and control eyes. To allow statistical analysis, the visual acuity was converted to a numerical grade: $6 / 6=1$, $6 / 9=2$, etc., as described previously [3]. It was also used to compare the photographic grading between the treated and control eyes. McNemar's test was used to compare the numbers of eyes that improved, remained the same, or deteriorated. For this analysis, improvement or deterioration were defined as a change of two lines or more in visual acuity on the Snellen chart. McNemar's test was also used to compare blind and seeing eyes. Blindness was defined as a visual acuity of $6 / 60$ or worse at two successive yearly assessments. This visual acuity was chosen, as $6 / 60$ vision in the better eye allows legal blind registration in the UK. The Chi-square test was used to compare the clinical characteristics of patients dying or surviving and those retaining vision or becoming blind. It was also used to compare the number of assessable eyes at each yearly interval.

For the visual acuity analysis, patients were first considered as a group. They were then subdivided into those with new vessels on the disc in both eyes and peripheral vessels only in both eyes and those asymmetrical for origin of new vessels. Because of the small number of asymmetrical eyes, these were not analysed separately.

\section{Results}

There were 107 patients from the six centres who entered the study. Of these, 77 completed five years of follow-up. Of the remainder, 13 were known to have died (four from renal failure, four from coronary heart disease, three following a stroke, one of cancer and one of unknown cause). Another 17 failed to complete the fiveyear follow up, two because they had the control eye treated, three were too ill to come to hospital, four were blind and the journey was too long, five had moved house and three because the ophthalmologist had moved hospitals.

\section{Medical conditions of the patients studied}

Age at diagnosis and duration of diabetes in 102 of the 107 patients are shown in Table 1 and their clinical details in Table 2. Sixty-three patients were diagnosed as diabetic before the age of 30 years and they were all insulin-dependent. Two-thirds of the patients had had their disease for $>15$ years. With increasing age of onset, the duration of diabetes before proliferative retinopathy developed became shorter. There were more male than female patients. At least 20 patients were non-insulin-dependent.

Of the coexistent medical conditions, neuropathy was the commonest, raised blood pressure was next, followed by raised blood urea (Table 3 ). However, none of the 39 with elevated urea had levels $>11.5 \mathrm{mmol} / 1$. Proteinuria was also common, but cardiac changes and claudication were uncommon. None of these condi- 
Blindness. Six patients became blind in both their treated and control eyes, four only in the treated eye when the control eye could still see and 28 in the control eye only, when the treated eye retained vision $(p<0.001)$. The difference was only significant when patients with disc new vessels were considered, although even in the peripheral new vessel group, more control eyes (five) than treated (one eye) became blind (Table 6). The causes of blindness were complications of new vessels in every case; vitreous haemorrhage, fibrous retinitis proliferans, retinal detachment and thrombotic glaucoma, either alone or in combination.

\section{Treatment effects}

Twenty-eight eyes had focal treatment only, 39 had scatter treatment alone, while 40 had both focal and scatter

$\begin{array}{rcccccccc}\text { No. of Patients } & 107 & 107 & 99 & 99 & 88 & 77 & 37 & 16 \\ \text { p } & \text { NS } & 0.05 & 0.001 & 0.001 & 0.001 & 0.001 & 0.01 & 0.05\end{array}$

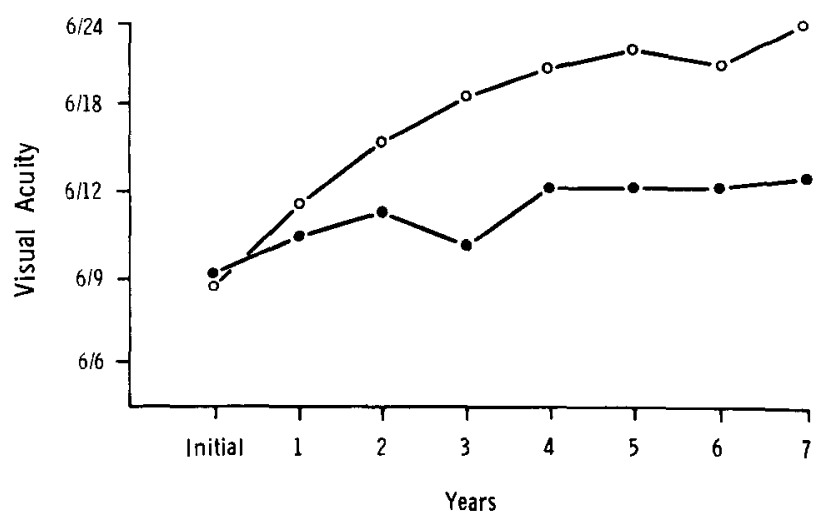

Fig. 1. Mean visual acuity of all eyes with new vessels. $\mathrm{O}-\mathrm{O}$ control eyes, $\longrightarrow$ treated eyes treatment. Forty-eight patients had all their treatment during the first month, 59 had one or more treatment sessions during subsequent years. As the number of burns to be given was not specified, in general, treatment given in the first 2 years was less than in later years, when experience with the instrument and reaction to treatment influenced the operator. The nine treated eyes with new vessels on the disc (one assymetrical eye, which went blind, had disc vessels in the treated eye) which became blind had fewer burns (mean 187) than the other 46 who retained vision (mean 316) (Table 7). Because of the size of the xenon-arc burns, 316 applications (probably even 150-200) invariably meant scatter treatment (though the initial treatment may have been focal). There were 12 patients who started with peripheral new vessels only and developed new vessels on the disc in their treated eye. These 12 had fewer burns (mean 117) before the development of the new vessels, compared with those who did not develop disc vessels (mean 189). Following the development of disc vessels, they had a further mean application of 211 burns (range 33-941). They also had more scatter treatment and less focal treatment.

\section{Photographic grading}

At the initial examination, there was no significant difference between treated and control eyes. Thereafter, at each yearly interval, there was a significant difference in at least some of the retinopathy features. Haemorrhages and microaneurysms were significantly less in the treated than control eyes from 1 to 5 years $(0.02<p<0.001)$, while hard exudates were less in the macular field only after the third year. It is of importance that the disc new vessel grading was highly significantly lower in treated than control eyes, reaching 0 grading (absent) by 7 years (Fig. 5). This was not because the new vessels changed

\begin{tabular}{|c|c|c|c|c|c|c|c|}
\hline $\begin{array}{l}\text { No. with disc } \\
\text { new vessels }\end{array}$ & 55 & 55 & 52 & 52 & 46 & 40 & 19 \\
\hline & NS & 0.02 & 0.001 & 0.001 & 0.001 & 0.001 & 0.01 \\
\hline No. with & 42 & 42 & 38 & 38 & 34 & 30 & 17 \\
\hline & NS & NS & NS & NS & NS & NS & NS \\
\hline
\end{tabular}

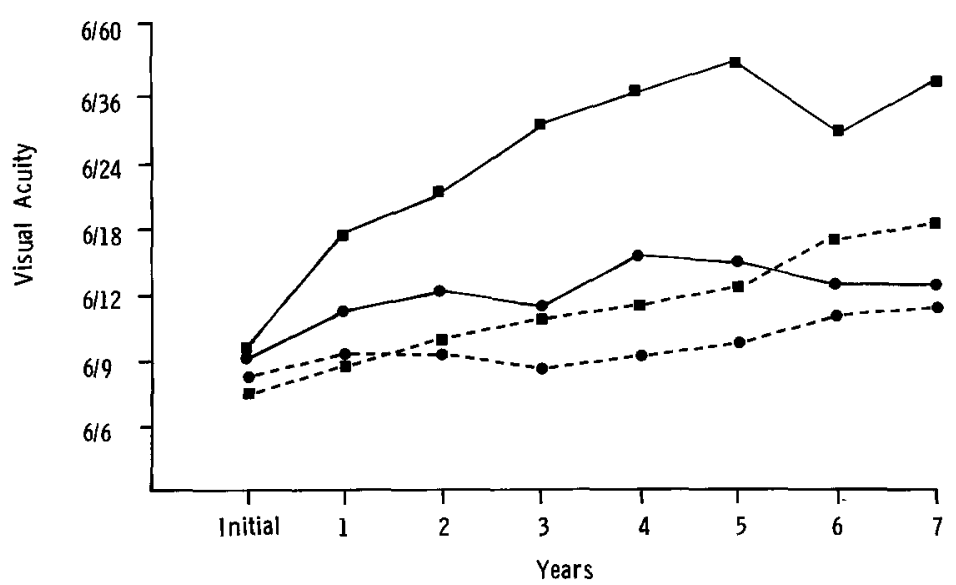

Fig. 2. Mean visual acuity of control eyes with disc new vessels $\longrightarrow$, treated eyes with disc new vessels $\longrightarrow$, control eyes with peripheral new vessels only -1, treated eyes with peripheral new vessels only -- 
Table 5. McNemar's test comparing eyes that improved and deteriorated in the treated and control groups

\begin{tabular}{|c|c|c|c|c|c|c|}
\hline & & & Control eye & & Total & $p$ \\
\hline & & & $\begin{array}{l}\text { Improved/ } \\
\text { same }\end{array}$ & Worse & & \\
\hline $\begin{array}{l}\text { After } 1 \\
\text { year }\end{array}$ & $\begin{array}{l}\text { Treated } \\
\text { eye }\end{array}$ & $\begin{array}{l}\text { Improved } \\
\text { /same }\end{array}$ & 71 & 19 & 90 & \\
\hline & & worse & 12 & 5 & 17 & \\
\hline & & Total & 83 & 24 & 107 & NS \\
\hline After 2 & Treated & Improved & 57 & 20 & 77 & \\
\hline & & worse & 8 & 14 & 22 & \\
\hline & & Total & 65 & 34 & 99 & $<0.05$ \\
\hline After 3 & Treated & Improved & 47 & 34 & 81 & \\
\hline & & worse & 6 & 12 & 18 & \\
\hline & & Total & 53 & 46 & 99 & $<0.001$ \\
\hline $\begin{array}{l}\text { After } 4 \\
\text { years }\end{array}$ & $\begin{array}{l}\text { Treated } \\
\text { eye }\end{array}$ & $\begin{array}{l}\text { Improved } \\
\text { /same }\end{array}$ & 35 & 30 & 65 & \\
\hline & & worse & 10 & 13 & 23 & \\
\hline & & Total & 45 & 43 & 88 & $<0.01$ \\
\hline $\begin{array}{l}\text { After } 5 \\
\text { years }\end{array}$ & $\begin{array}{l}\text { Treated } \\
\text { eve }\end{array}$ & Improved & 29 & 28 & 57 & \\
\hline & & worse & 6 & 13 & 19 & \\
\hline & & Total & 35 & 41 & 76 & $<0.001$ \\
\hline After 6 & Treated & Improved & 14 & 12 & 26 & \\
\hline & & worse & 3 & 8 & 11 & \\
\hline & & Total & 17 & 20 & 37 & $<0.05$ \\
\hline
\end{tabular}

McNemar's test: Chi-square $=\frac{[(b-c)-1]^{2}}{b+c}$ where $b=$ number worse in control eye and improved or same in treated eye and $c=$ number improved or the same in the control eye and worse in the treated eye. $p$ refers to the test for difference between treated and control eyes. Improved $=$ improved by two lines or more on Snellen chart; worse $=\mathrm{de}-$ teriorated by two lines or more on Snellen chart; NS = not significant. to fibrous retinitis proliferans, but rather because they improved, since in the treated eyes, less fibrous tissue formed (Fig. 6). Indeed, the mean grading for fibrous tissue remained unchanged in the treated eyes while it deteriorated in the control eyes, so that it became significantly worse at $3,4,5$ and 7 years $(0.05<p<0.001)$. More control eyes became unassessable than treated ones; vitreous haemorrhage, thrombotic glaucoma and detachment being the principle causes. The difference in assessability was significant at 3,4 and 5 years $(p<$ $0.05)$.

\section{Discussion}

The aim of this study was to establish the value of xenon-arc photocoagulation in the treatment of diabetic retinopathy. In allowing a certain amount of freedom in the treatment technique, it was also aimed at finding the best possible treatment method. In both these aims, the trial was successful.

The report re-emphasizes the result of three shortterm [2-4] and one long-term randomised controlled clinical studies [5] in the treatment of proliferative diabetic retinopathy. Of the previous studies, those of the "Diabetic Retinopathy Study Group" are the most important, because of the highly significant results obtained in a study of more than 1700 patients $[2,5]$. It is noteworthy that the cumulative rate of severe visual loss (similar to blindness in our study) in the control eyes of that study was $34 \%$ at 5 years, similar to that of the present study (34 out of 107 eyes). The $15 \%$ blindness in their treated eyes is also similar to that found in the United Kingdom. The results are slightly worse than those found by Asher et al [9], who analysed one group's result over a long period of time, though this was not a randomised controlled clinical study. Part of the reason for Asher et al's better results may be that the correct

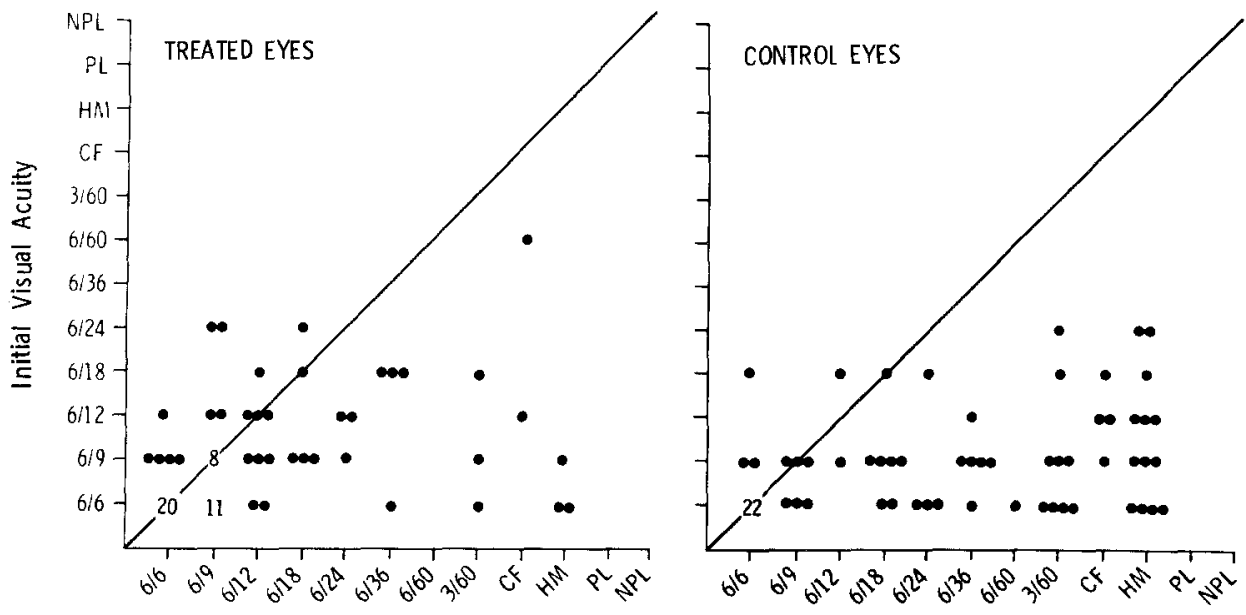

5th Year Visual Acuity
Fig.3. Initial and 5-year visual acuity in 77 treated and control eyes with proliferative retinopathy at entry into the study. Each eye is represented by a dot (or by number if over six in one spot). Diagonal: no change line, $\mathrm{CF}=$ count fingers, $\mathrm{HM}=$ hand movements, $\mathrm{PL}=$ perception of light, $\mathrm{NPL}=$ no perception of light 

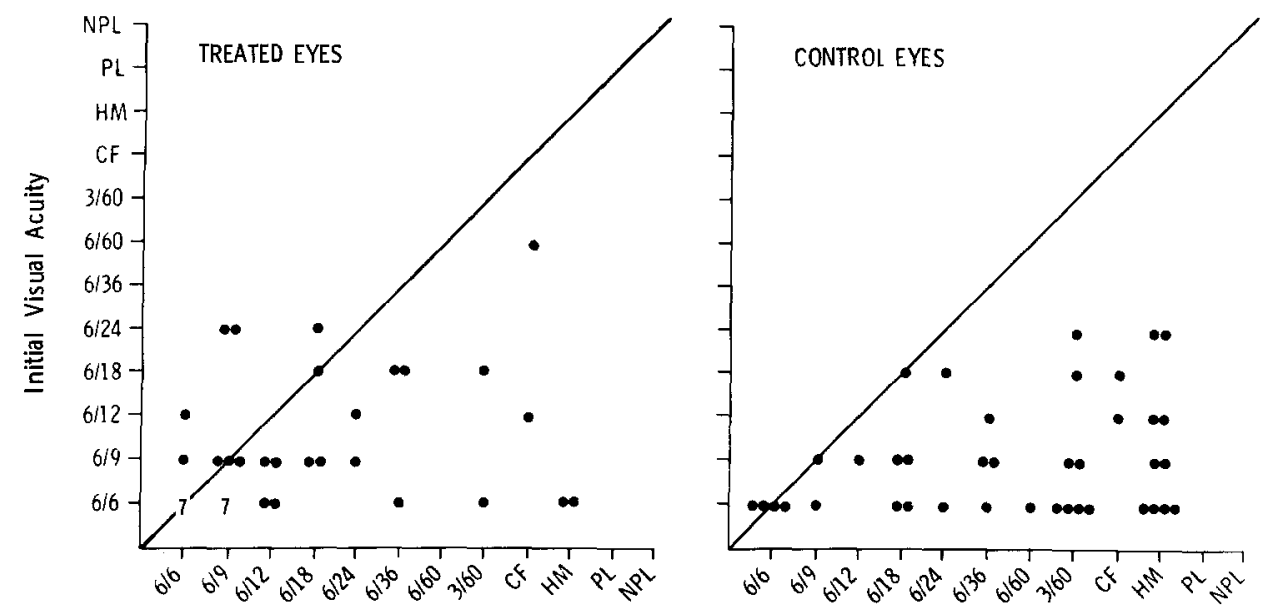

Fig. 4. Initial and 5-year visual acuity of 40 treated and 39 eyes with disc new vessels at entry into the study Annotation as in Figure 3

5th Year Visual Acuity

Table 6. Blindness in eyes with new vessels

\begin{tabular}{lllll}
\hline New vessels & \multicolumn{2}{l}{ No. of blind eyes } & $p$ \\
\cline { 2 - 4 } & $\begin{array}{l}\text { Both } \\
\text { eyes }\end{array}$ & $\begin{array}{l}\text { Treated } \\
\text { eyes } \\
\text { only }\end{array}$ & $\begin{array}{l}\text { Control } \\
\text { eyes } \\
\text { only }\end{array}$ & \\
\hline On disc & 6 & 2 & 22 & $<0.001$ \\
Peripheral only & 0 & 1 & 5 & NS \\
Asymmetrical & 0 & 1 & 1 & NS \\
\hline Total & 6 & 4 & 28 & $<0.001$
\end{tabular}

$\mathrm{NS}=$ not significant

Table 7a. Effect of treatment on eyes with disc new vessels

\begin{tabular}{lcc}
\hline & No. of eyes & $\begin{array}{l}\text { No. of burns } \\
\text { mean (range) }\end{array}$ \\
\hline Blind & 9 & $187(68-336)$ \\
Not blind & 46 & $316(25-860)$ \\
\hline Total & 55 & \\
\hline
\end{tabular}

Table $7 \mathbf{b}$. Development of disc new vessels (absent at entry)

\begin{tabular}{llll}
\hline & $\begin{array}{l}\text { Treated } \\
\text { eyes }\end{array}$ & $\begin{array}{l}\text { No. of burns } \\
\text { mean (range) }\end{array}$ & $\begin{array}{l}\text { Control } \\
\text { eyes }\end{array}$ \\
\hline $\begin{array}{l}\text { Disc vessels developed } \\
\begin{array}{l}\text { Disc vessels did not } \\
\text { develop }\end{array}\end{array}$ & 12 & $117(12-276)$ & 21 \\
\hline Total & 42 & $189(33-580)$ & 21 \\
\hline
\end{tabular}

treatment is most likely to be utilised reliably in a small group working together and devoted to the management of diabetic eye disease.

In this study, only xenon treatment was used while Hercules et al used argon only [4]. The Diabetic Retinopathy Study Group used both xenon and argon [2, 5, 10]. The results with xenon were slightly, but not significantly, better in preventing blindness, but more xenon

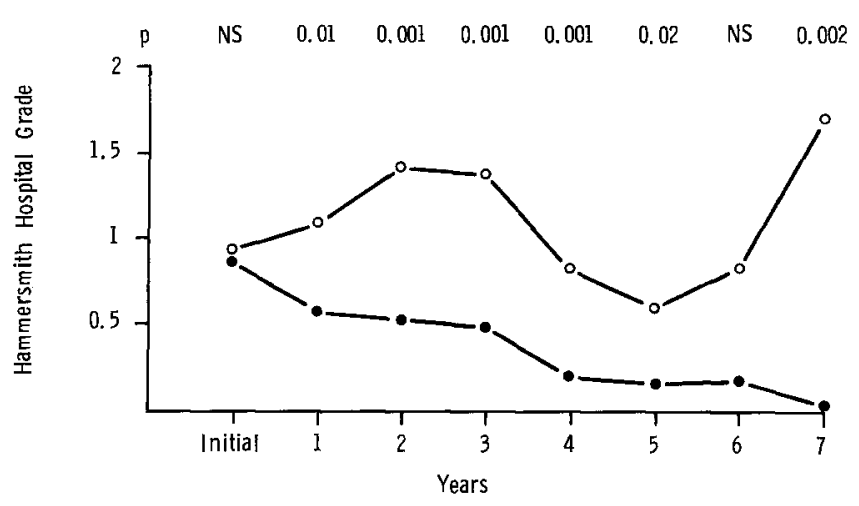

Fig.5. Mean new vessel grading in the disc field in treated and control $(\mathrm{O}-\mathrm{O})$ eyes. NS: not significant

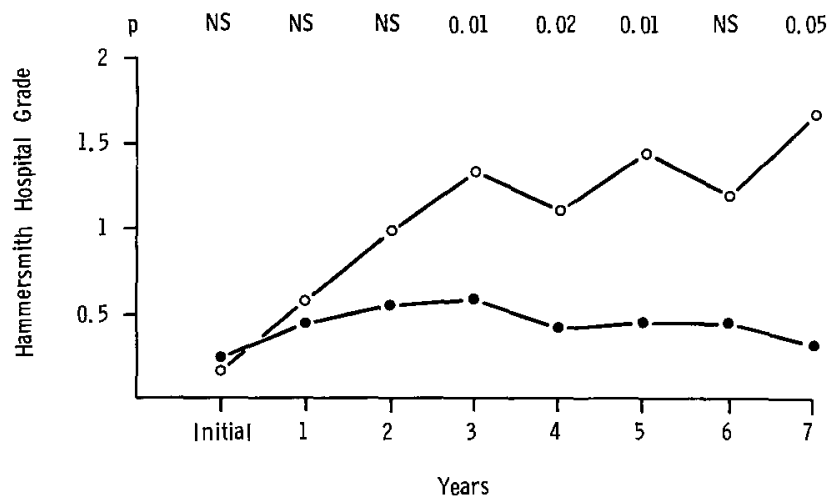

Fig. 6. Mean grading of fibrous retinitis proliferens in the disc field for treated $(-0)$ and control $\left(\mathrm{O}^{-} \mathrm{O}\right)$ eyes. NS: not significant.

than argon-treated eyes lost a few lines of vision as a result of treatment [2]. The reason may have been the protocol designed by the Diabetic Retinopathy Study Group which specified that focal treatment should be given to lesions if they were responsible for macular oedema [10]. Such lesions would commonly be within one disc diameter of the fovea - an area avoided in the present study. 
The second aim of the present study was to find a method of treatment which would be acceptable to all in clinical practice. The freedom allowed in the study prevented a randomised comparison of methods, but the results provide a strong indication for extensive treatment rather than a scattered one and for scatter plus focal treatment for peripheral new vessels. The study also showed (probably because xenon only was used) that direct treatment of vessels on the disc or feeder vessel treatment is rarely indicated. Indeed the method of treatment advised by the Diabetic Retinopathy Study Group study [10] is not now used, as clinical practice clearly showed that more extensive treatment and not direct treatment of disc vessels is more advantageous [3]. The idea of scatter treatment alone as a useful method of management of proliferative diabetic retinopathy originates from Aiello et al. [11].

The present study, like those previously published, emphasises the effectiveness of photocoagulation in patients with new vessels arising from the optic disc. When untreated, these have a poor prognosis, even in those with early lesions [12]. Caird et al. [13] reported that within 3 years of their first vitreous haemorrhage, one-third of patients were blind in both eyes. Vitreous haemorrhage is an early complication of disc new vessels, but occurs relatively late only in those with peripheral new vessels. The latter only bleed when they grow forward off the surface of the retina. Nevertheless, flat new vessels should probably be treated, because it is easy to do so, and because as shown here, within 5 years, $50 \%$ develop disc new vessels when untreated. Twenty-eight percent of the treated eyes also developed disc new vessels; they tended to be the eyes which had received less treatment, and further treatment destroyed these vessels or caused regression.

It is not surprising that in this study, medical conditions did not influence visual outcome. New vessels arise in response to a non-perfused retina; they are not the direct result of high blood pressure or poor metabolic control. It is likely that, early in diabetes, these factors are important, as they may lead to more rapid and widespread vascular occlusion, but this has not yet been proven.

It is of interest that only $14 \%$ of the patients died during the follow-up period. The 5-year mortality in the study by Davis et al. [14] in those with proliferative retinopathy was $50 \%$. However, the patients in that study were selected on ophthalmic criteria only, while here only those likely to survive 5 years were entered.

Finally, the large majority of patients in this study had $6 / 12$ or better vision at entry into the study and were not aware of any visual impairment. Yet one-third of all untreated eyes were blind with a visual acuity of $6 / 60$ or worse for two consecutive yearly assessments after 5 years of follow-up. This emphasises the need for screening of patients, especially those with young onset insulin-dependent diabetes, for proliferative retinopathy. Early lesions are easy to treat and, with adequate treatment, visual prognosis is predictably good.

Acknowledgements. This work was supported by: The British Diabetic Association, The Wellcome Trust and The Department of Health and Social Security.

\section{References}

1. Meyer-Schwickerath G (1979) Lichtkoagulation. Enke Verlag, Stuttgart

2. Diabetic Retinopathy Study Research Group (1976) Preliminary report on effects of photocoagulation therapy. Am J Ophthalmol 81:383-397

3. British Multicentre Study Group (1977) Proliferative diabetic retinopathy; treatment with xenon arc photocoagulation. Br Med $\mathbf{J} 1$ : 739-742

4. Hercules BL, Gayed II, Lucas SB, Jaecock J (1977) Peripheral retinal ablation in the treatment of proliferative diabetic retinopathy. Br J Ophthalmol 61: 555-563

5. Diabetic Retinopathy Study Research Group (1981) Photocoagulation treatment of proliferative diabetic retinopathy. Diabetic Retinopathy Study, report No. 8. Ophthalmology 88: 583-600

6. Oakley NW, Hill DW, Joplin GF, Kohner EM, Fraser TR (1967) Diabetic retinopathy I: assessment of severity and progression with a set of standard fundus photographs. Diabetologia 3: 402-405

7. Kohner EM, Panissett A, Cheng H, Fraser TR (1971) Diabetic retinopathy. New vessels arising from the optic disc I: grading system and natural history. Diabetes 20: $816-823$

8. Armitage $P$ (1971) Statistical methods in medical research. Blackwell, Oxford, $\mathrm{p} 128$

9. Asher R, Hunt S, Hamilton AM, Townsend C, Blach RK, Khoury D, Kohner EM, Morris DV (1981) Photocoagulation for optic disc new vessels in diabetic retinopathy. Int Ophthal 3:79-85

10. Diabetic Retinopathy Study Research Group (1981) Design methods and baseline results. Invest Ophthalmol Vis Sci 21:149-203

11. Aiello LM, Beetham WP, Baodimos MC, Chazan BI, Bradley RF (1969) Ruby laser photocoagulation in the treatment of proliferative diabetic retinopathy. In: Goldberg $M$, Fine $S$ (eds) Treatment of diabetic retinopathy. United States Department of Public Health, pp 437-463

12. Deckert T, Simonson E, Poulsen JE (1967) Prognosis of proliferative retinopathy in juvenile diabetes. Diabetes 16: 728-737

13. Caird FI, Burditt AF, Draper GJ (1968) Diabetic retinopathy. A further study of prognosis for vision. Diabetes 17:121-123

14. Davis MD, Hiller R, Magli YL, Podgor MJ, Ederer F, Harris WA, Long JW, Haug GA (1979) Prognosis for life in patients with diabetes in relation to severity of retinopathy. Trans Amer Ophth Soc 77: $144-170$

Received: 12 April 1983

and in revised form: 16 November 1983

Dr. E. M. Kohner

Department of Medicine

Hammersmith Hospital

Du Cane Road

London, W12 OHS

UK. 